\title{
Prevalence of Mediterranean Fever Gene Mutations in Turkish Cypriot Population
}

\author{
Nilüfer GALİP, ${ }^{1}$ Ceyhun DALKAN,${ }^{1}$ Ayşe TERALI,${ }^{1}$ Nazan ÇOBANOĞLU, ${ }^{2}$ \\ Ayfer ÜLGENALP, ${ }^{3}$ Nerin BAHÇECİLER, ${ }^{1}$ Salih KAVUKÇU ${ }^{4}$ \\ ${ }^{1}$ Department of Pediatrics, Near East University Faculty of Medicine, Lefkoşa, Turkish Republic of Northern Cyprus \\ ${ }^{2}$ Department of Pediatrics, Division of Pediatric Pulmonology, Medical Faculty of Ankara University, Ankara, Turkey \\ ${ }^{3}$ Department of Medical Genetics, Medical Faculty of Dokuz Eylül University, İzmir, Turkey \\ ${ }^{4}$ Department of Pediatrics, Division of Pediatric Nephrology and Rheumatology, Medical Faculty of Dokuz Eylül University, İzmir, Turkey
}

ABSTRACT

Objectives: This study aims to determine the carrier frequency and the most common mutations of the Mediterranean fever (MEFV) gene in healthy Cypriot population of Turkish origin.

Patients and methods: A total of 296 healthy participants (102 males, 194 females; median age 30 years; range 1 to 81 years) were evaluated. The exon 2, 3, 5 and 10 of MEFV genes were amplified by polymerase chain reaction.

Results: The participants demonstrated an extremely high carrier rate (12.5\%). Most commonly detected mutations were E148Q and A74S, with rates of $7.3 \%$ and $2.8 \%$, respectively.

Conclusion: Mediterranean fever gene mutation types and carrier rates in Turkish Cypriot population are different than other Mediterranean populations in the region. MEFV mutation carriage is frequent in North Cyprus and familial Mediterranean fever might be one of the causes for end stage renal disease in Turkish Cypriots.

Keywords: Cyprus; Familial Mediterranean fever; Mediterranean fever gene; mutations.

Familial Mediterranean fever (FMF) is an autosomal recessively inherited disease characterized by autoinflammatory episodes of recurrent fever and serosal inflammation of the periton, pleura, and synovia. The disease is caused by mutations in Mediterranean fever gene (MEFV) which has been cloned in 1997. ${ }^{1}$ MEFV gene is located on the short arm of chromosome 16, consists of 10 exons and encodes a protein of 781 amino-acids named Pyrin/Marenostrin. This protein is expressed in granulocytes and plays an essential role in the inflammatory response. Although phenotypegenotype correlations of the disease have not been clarified definitely, current data suggest that expression of more severe disease and increased susceptibility to amyloidosis are detected in patients who have the M694V mutation. ${ }^{2}$

Familial Mediterranean fever usually affects Mediterranean populations like Ashkenazi Jews, Armenians, Turks, Italians, and Iranians. In Israel, there are different prevalence rates according to the origin of the populations. Disease frequency is 1:200 in North African Jews whereas 1:160,000 in Ashkenazi Jews originating from Central Europe. ${ }^{3,4}$ In the Turkish population, 
epidemiological studies have shown that the prevalence of FMF is approximately 1:1,000.

Cyprus is the third largest island in the Mediterranean Sea with two separated communities; Turkish and Greek Cypriots. Turkish Cypriots live in the north of the island in the Turkish Republic of Northern Cyprus with a population of approximately 300,000, while Greek Cypriots live in the south in the Republic of Cyprus. ${ }^{5}$ The prevalence of MEFV mutations in Greek Cypriots with FMF disease was first reported in 2002. ${ }^{6}$ Prevalence of MEFV mutations in Turkish Cypriot population has not been studied yet. Therefore, in this study, we aimed to determine the carrier frequency and the most common mutations of the MEFV gene in healthy Cypriot population of Turkish origin.

\section{PATIENTS AND METHODS}

A total of 296 healthy subjects (102 males, 194 females; median age 30 years; range 1 to 81 years) were included and tested for mutations in MEFV gene. The study population was selected between October 2013 and June 2014 from healthy adults or children who (i) admitted to the blood sampling room of The Near East University Hospital and agreed to give an extra tube of blood sample; (ii) were Turkish Cypriots born from both Cypriot parents whose ancestors originated from Cyprus for three generations; (iii) had no personal or family history of FMF; (iv) signed the informed consent form. After enrollment, participants were evaluated with a questionnaire seeking information on birth place, inherited genetic and rheumatologic diseases, history of apendectomy and having any of the Tel-Hashomer criteria (peritonitis, arthritis, scrotal inflammation, chest pain, erysipeloid skin eruptions, or myalgia). The study was approved by the Ethics Committee of Near East University. The study was conducted in accordance with the principles of the Declaration of Helsinki.

Whole blood was collected in ethylenediaminetetraacetic acid tubes and transferred to Dokuz Eylul University Genetic Laboratory. Genomic deoxyribonucleic acid from peripheral blood cells was extracted using the QIAamp Blood Kit (QIAGEN GmbH, Hilden, Germany) according to the manufacturer's instructions. The exon 2, 3, 5 and 10 of MEFV genes were amplified by the polymerase chain reaction using HelixAmp ${ }^{\mathrm{TM}}$ Ready-2x-MultiPlex v.2.0 polymerase chain reaction mastermix (Nanohelix Co. Ltd, Seoul South Korea) in $50 \mu \mathrm{L}$ of solution containing $100 \mathrm{ng}$ of genomic deoxyribonucleic acid. The amplification was performed on thermocycler (Perkin Elmer 9700), with a predenaturing procedure for 10 minutes at $94{ }^{\circ} \mathrm{C}$ for 35 cycles (denaturing at $94{ }^{\circ} \mathrm{C}$ for 45 seconds, annealing at $58{ }^{\circ} \mathrm{C}$ for 45 seconds, and extension at $72{ }^{\circ} \mathrm{C}$ for 50 seconds), followed by an additional seven-minute incubation at $72{ }^{\circ} \mathrm{C}$. Following selective amplification of exon 2, 3, 5 and 10 with specific M13 tagged primers (Table 1), products were run in a $2 \%$ agarose gel containing ethidium bromide and visualized under ultraviolet (UV) light. Polymerase chain reaction products were purified using ExoSAP-IT (USB Corporation, Cleveland, $\mathrm{OH}, \mathrm{USA})$. Direct sequencing reactions were performed using BigDye Terminator v3.1 Cycle Sequencing Kit with M13 F\&R primers and analyzed in ABI Prism 3130 Genetic Analyzer (Applied Biosystems, Foster City, CA, USA). The MEFV exon sequences were aligned and analyzed using SeqScape 2.5 software (Applied Biosystems, Foster City, CA, USA).

\begin{tabular}{|lll}
\hline \multicolumn{2}{|l}{ Table 1. Primers } \\
\hline \multicolumn{2}{l}{ M13 tagged primers for Mediterranean fever gene sequencing analysis } \\
\hline Exon 2 & Forward & TGTAAAACGACGGCCAGTAACTTTAATATCCAAGGGGATTC \\
Exon 2 & Reverse & CAGGAAACAGCTATGACCTTCTCTGCAGCCGATATAAAGTA \\
Exon 3 & Forward & TGTAAAACGACGGCCAGTGAACTCGCACATCTCAGGC \\
Exon 3 & Reverse & CAGGAAACAGCTATGACCAAGGCCCAGTGTGTCCAAGTC \\
Exon 5 & Forward & TGTAAAACGACGGCCAGTTATCGCCTCCTGCTCTGGAATC \\
Exon 5 & Reverse & CAGGAAACAGCTATGACCCACTGTGGGTCACCAAGACCAAG \\
Exon 10 & Forward & TGTAAAACGACGGCCAGTCCAGAAGAACTACCCTGTCCC \\
Exon 10 & Reverse & CAGGAAACAGCTATGACCTCCTCCTCTGAAATCCATGG \\
\hline
\end{tabular}




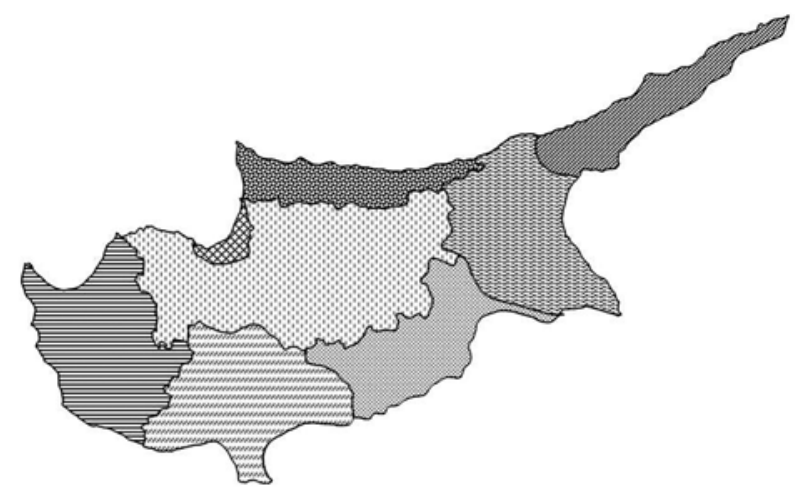

\begin{tabular}{lc}
\hline District & $\%$ \\
\hline Kyrenia & 10.3 \\
Nicosia & 54.3 \\
Larnaca & 13.4 \\
Laphou & 1.4 \\
Laphos & 8.9 \\
Limassol & 1.4 \\
Turkish Cypriots born in other & 3.8 \\
commonwealth countries & 3.8
\end{tabular}

Figure 1. Distribution of the participants according to birth places.

\section{Statistical analysis}

Statistical analyses were performed using the PASW version 17.0 software (SPSS Inc., Chicago, IL, USA). Descriptive statistics were expressed as mean standard deviation, median and range. Prevalence rates were expressed as percentages.

Table 2. Mutation/polymorphism allele frequencies of the population

\begin{tabular}{lc}
\hline Mutation/polymorphism & $\%$ \\
\hline R202Q & 15.8 \\
E148Q & 4 \\
A744S & 1.5 \\
V726A & 1 \\
M694V & 0.5 \\
M694I & 0.5 \\
R761H & 0.5 \\
R408Q & 0.5 \\
E167D & 0.3 \\
F479L & 0.3 \\
69S & 0.16 \\
R653H & 0.16 \\
\hline
\end{tabular}

\section{RESULTS}

Distribution of participants' birth places in Cyprus are shown in Figure 1. The mutation carriage frequency detected among this healthy population was $12.5 \%$. Detailed results of MEFV genes allele frequencies are presented in Table 2. The most commonly detected mutations were $\mathrm{E} 148 \mathrm{Q}$ and $\mathrm{A} 744 \mathrm{~S}$, with the percentages of $7.3 \%$ and $2.8 \%$, respectively (Table 3). Interestingly, genetic polymorphism in the R202Q gene was detected in $25.7 \%$ of the study population. A comparison of the common mutations in two neighboring countries are shown in Table 4. There were no statistically significant association with homozygous and compound heterozygous mutation carriage and presence of FMF symptoms in our study population (Figure 2). A comparison of the allele frequencies of MEFV mutations between healthy Turkish Cypriots and other populations from the region are demonstrated in Table 5.

\begin{tabular}{lr} 
Table 3. Distributions of Mediterranean fever mutations \\
\hline Distribution of Mediterranean fever mutations & $\%$ \\
\hline E148Q heterozygous & 7.3 \\
A744S heterozygous & 2.8 \\
V726A heterozygous & 1.7 \\
R761H heterozygous & 0.7 \\
M694I heterozygous & 0.7 \\
M694V heterozygous & 0.3 \\
M680I/C heterozygous & 0.3 \\
R653H heterozygous & 0.3 \\
R408Q heterozygous & 0.3 \\
M694I heterozygous & 0.3 \\
69S heterozygous & 0.3 \\
F479L V726A compound heterozygous & 0.3 \\
E167D + F479L compound heterozygous & 0.3
\end{tabular}

Table 4. The comparison of first three most common mutations of North Cyprus, Turkey and Israel

\begin{tabular}{lcc}
\hline Country & Mutation types & $\%$ \\
\hline North Cyprus & E148Q & 7.3 \\
& A744S & 2.8 \\
Turkey & V726A & 1.7 \\
& E148Q & 3.6 \\
Israel & M694V & 2.6 \\
& P369S & 1 \\
& E148Q & 6 \\
& M694V & 1.6 \\
& V726A & 1.2 \\
\hline
\end{tabular}




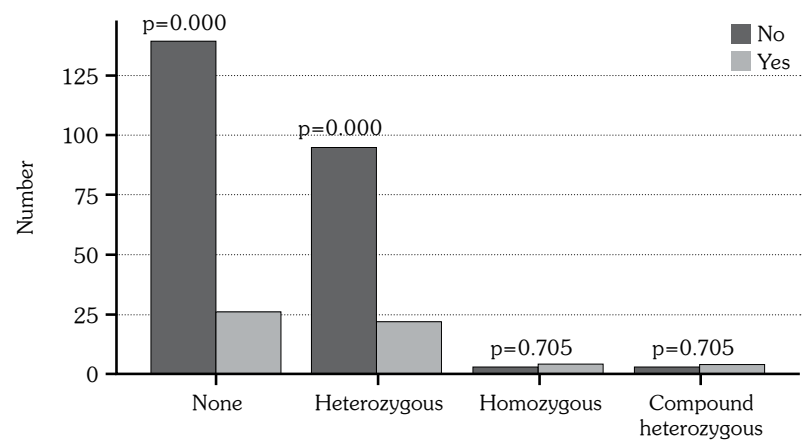

Figure 2. Association between mutation carriage status and symtomatic Familial Mediterranean fever.

\section{DISCUSSION}

Cyprus has a rich history with many different ethnicities and cultures posing complicated genetic features. Turkish Cypriots are ethnic Turks living in or originating from Cyprus. Following the Ottoman conquest of the island in 1571 , about 30,000 Turkish settlers were given land once they arrived in Cyprus. ${ }^{8,9}$ In 1983, the Turkish Cypriots declared their own state in the north, the Turkish Republic of Northern Cyprus. There are limited studies conducted in the south part of the island on inherited diseases, particularly on thalassemia and two studies on MEFV mutation carriage in Greek Cypriot FMF patients. ${ }^{6,7}$ Although there are approximately 220 recorded patients with end stage renal disease in North Cyprus, etiology is unknown in $29.8 \%$ of them..$^{10}$ Moreover, the incidence of FMF disease and amyloidosis in Turkish Cypriot population is unknown. We hypothesized that MEFV mutation carriage is frequent in North Cyprus and FMF might be one of the causes for end stage renal disease. This preliminary study may shed light on the frequency of
MEFV mutation carriage rates and types of mutations in healthy Turkish Cypriot individuals, thereby improve the awareness of physicians for screening and diagnosing the disease.

Only a limited number of studies evaluated the prevalence of MEFV gene mutations in healthy populations. ${ }^{11,12}$ Most studies were performed on clinically diagnosed FMF patients. Results of current study were therefore compared to the results of those two healthy population studies of Turkey and Israel. MEFV mutations of Greek Cypriots with FMF were also found in our study; however, the frequencies were not compared due to the lack of healthy population results. The most common mutations found in our study population were E148Q and A744S, with the rates of 7.3\% and $2.8 \%$, respectively. Unexpectedly, $\mathrm{R} 202 \mathrm{Q}$ polymorphism was detected in $25.7 \%$ of the population which had been described in previous studies..$^{13,14}$ The most common mutation was E148Q in our study population. E148Q mutation had been reported to be the most common in Turkey and Israel as well, but with a higher frequency (7.3\%) in Turkish Cypriots. ${ }^{11,12}$ Another interesting finding of the current study was the second most common mutation of A744S, which has been detected rarely in other neighboring Mediterranean countries. The third most common mutation detected in Turkish Cypriot population was V726A, with a percentage of $1.7 \%$, which was also higher than that in Turkey. Frequency of $\mathrm{M} 694 \mathrm{~V}$ mutation was reported to be $2.6 \%$ in Turkey. ${ }^{[12]}$ This mutation is known as the highest risk factor for the development of amyloidosis. Carriage rate of this mutation was detected as $0.3 \%$ in Turkish Cypriot population in this study.

According to the allele frequencies of the common mutations, M694V was low in Turkish

Table 5. Comparison of the allele frequencies of Mediterranean fever mutations in healthy individuals between Turkish Cypriots, Anatolian Turks and Israeli Jewish

\begin{tabular}{|c|c|c|c|c|}
\hline \multirow[t]{2}{*}{ Mutation/polymorphism (Alleles) } & Turkish Cypriots & $\begin{array}{c}\text { Anatolian Turks }{ }^{16} \\
(\mathrm{n}=200)\end{array}$ & $\begin{array}{c}\text { Anatolian Turks }{ }^{15} \\
(\mathrm{n}=370)\end{array}$ & $\begin{array}{l}\text { Israeli Jewish }{ }^{11} \\
\quad(n=326)\end{array}$ \\
\hline & $\%$ & $\%$ & $\%$ & $\%$ \\
\hline E148Q & 4 & 6 & NA & 5.8 \\
\hline A744S & 1.5 & NA & NA & NA \\
\hline V726A & 1 & 1 & 1.6 & 1.2 \\
\hline M694V & 0.5 & 1.5 & 2.1 & 1.8 \\
\hline M680I & 0.5 & 2.5 & 0.5 & NA \\
\hline
\end{tabular}


Cypriots compared to Anatolian Turks and Israeli Jewish populations. On the other hand, allele frequencies of V726A and E148Q were similar between those three Mediterranean populations.

In the current study, the frequency of homozygous and compound heterozygous mutation carriers were $2.4 \%$, which is higher than that in Turkey. There were no statistically significant associations with homozygous and compound heterozygous mutation carriage and presence of FMF symptoms in our study population. This is probably due to the low number of homozygous mutation carrier participants $(p=0.705)$. Those with heterozygous mutations were significantly symptom free $(p=0.0000)$. Interestingly, one of the participants carrying homozygous $\mathrm{R} 202 \mathrm{Q}$ polymorphism had already developed severe disease symptoms without any diagnosis.

In conclusion, the current study demonstrated a high MEFV gene mutation carrier rate of $12.5 \%$ in the Turkish population of Cyprus. Although $\mathrm{R} 202 \mathrm{Q}$ is currently accepted as a polymorphism, it was detected in $25.7 \%$ of the study population with a symptomatic patient demonstrating homozygous carriage of this polymorphism. Thus, we showed that MEFV gene mutation types and carrier rates in Turkish Cypriot population are different than other Mediterranean populations in the region. In addition, findings of our study suggest close follow-up of $\mathrm{R} 202 \mathrm{Q}$ polymorphism carriers.

\section{Declaration of conflicting interests}

The authors declared no conflicts of interest with respect to the authorship and/or publication of this article.

\section{Funding}

The authors received no financial support for the research and/or authorship of this article.

\section{REFERENCES}

1. Ancient missense mutations in a new member of the RoRet gene family are likely to cause familial Mediterranean fever. The International FMF Consortium. Cell 1997;90:797-807.

2. Tunca M, Akar S, Onen F, Ozdogan H, Kasapcopur $O$, Yalcinkaya F, et al. Familial Mediterranean fever (FMF) in Turkey: results of a nationwide multicenter study. Medicine (Baltimore) 2005;84:1-11.
3. Pras E, Livneh A, Balow JE Jr, Pras E, Kastner DL, Pras $M$, et al. Clinical differences between North African and Iraqi Jews with familial Mediterranean fever. Am J Med Genet 1998;75:216-9.

4. Heller H, Sohar E, Pras M. Ethnic distribution and amyloidosis in familial Mediterranean fever (FMF). Pathol Microbiol (Basel) 1961;24:718-23.

5. Dalkan C, Galip N, Tekguc H, Cobanoglu N, Bahceciler N. High prevalence of allergy in North Cypriot children. Paediatr Int Child Health 2014;34:37-42.

6. Deltas CC, Mean R, Rossou E, Costi C, Koupepidou $\mathrm{P}$, Hadjiyanni I, et al. Familial Mediterranean fever (FMF) mutations occur frequently in the Greek-Cypriot population of Cyprus. Genet Test 2002;6:15-21.

7. Neocleous V, Costi C, Kyriakou C, Kyriakides TC, Shammas C, Skordis N, et al. Familial Mediterranean fever associated with MEFV mutations in a large cohort of Cypriot patients. Ann Hum Genet 2015;79:20-7.

8. Welin G, Ekelund C. The UN in Cyprus: Swedish Peace-keeping Operations 1964-1993, Hurst \& Company; 2004

9. Hussein S. Yesterday \& Today: Turkish Cypriots of Australia; 2007.

10. Connor TM, Oygar DD, Gale DP, Steenkamp R, Nitsch D, Neild GH, et al. Incidence of end-stage renal disease in the Turkish-Cypriot population of Northern Cyprus: a population based study. PLoS One 2013;8:e54394.

11. Feld O, Livneh A, Shinar Y, Berkun Y, Lidar M. MEFV mutation carriage in Israeli Jewish individuals from ethnicities with low risk for familial Mediterranean fever. J Hum Genet 2009;54:369-71.

12. Yalcinkaya F, Duzova A, Gonen S, Özçakar B, Baskın E, Özkaya $\mathrm{O}$, et al. Türk popülasyonun MEFV mutasyonlarının sıklı̆̆. Poster no: 20 IV. National Congress of Transplantation Immunology and Genetics, Çeşme, İzmir, Turkey; 2013.

13. Yigit S, Karakus N, Tasliyurt T, Kaya SU, Bozkurt N, Kisacik B. Significance of MEFV gene R202Q polymorphism in Turkish familial Mediterranean fever patients. Gene 2012;506:43-5.

14. Cankaya T, Bora E, Torun Bayram M, Ülgenalp A, Kavukçu S, Türkmen MA, et al. Clinical Significance of R202Q Alteration of MEFV Gene in Children With Familial Mediterranean Fever. Arch of Rheum 2015;30:1-5.

15. Atagunduz MP, Tuglular S, Kantarci G, Akoglu E, Direskeneli H. Association of FMF-related (MEFV) point mutations with secondary and FMF amyloidosis. Nephron Clin Pract 2004;96:c131-5.

16. Yilmaz E, Ozen S, Balci B, Duzova A, Topaloglu $\mathrm{R}$, Besbas $\mathrm{N}$, et al. Mutation frequency of Familial Mediterranean Fever and evidence for a high carrier rate in the Turkish population. Eur $\mathrm{J}$ Hum Genet 2001;9:553-5. 